\title{
Integrated Nematode Management in Chickpea against Meloidogyne Incognita - A View Point
}

\author{
Shaon Kumar Das \\ ICAR Research Complex for NEH Region, Sikkim Centre, Sikkim
}

Copyright (C) 2015 by authors, all rights reserved. Authors agree that this article remains permanently open access under the terms of the Creative Commons Attribution License 4.0 International License

\begin{abstract}
Early researchers identified key concepts and developed tactics for multiple option management of nematodes. Traditional management tactics include host resistance (where available), cultural tactics such as rotation with nonhosts, sanitation and avoidance, and destruction of residual crop roots and judicious use of nematicides. There have been advances in biological control of nematodes, but field-scale exploitation of this tactic remains to be realized. New technologies and resources are currently becoming central to the development of sustainable systems for nematode-pest-crop management, molecular diagnostics for nematode identification, genetic engineering for host resistance, and the elucidation and application of soil biology for general integrated cropping systems. The latter strategy includes use of nematode-pest antagonistic cover crops, animal wastes, and limited tillage practices that favor growth-promoting rhizobacteria, earthworms, predatory mites, and other beneficial organisms while suppressing parasitic nematodes and other plant pathogens. Certain rhizobacteria may induce systemic host resistance to nematodes and, in some instances, to foliage pathogens. The systems focusing on soil biology hold great promise for sustainable crop-nematode management, but only a few research programs are currently involved in this labor-intensive endeavor.
\end{abstract}

Keywords Host Resistance, Genetic Engineering, Nematicides, Sanitation, Tillage, Antagonistic Cover Crops

\section{Introduction}

During early nineteen century people discussed a wide range of tactics for nematode management that are surprisingly similar to those available today: sterilization of soil by starvation, including the use of nonhosts plants, the potential of trap crops, compost, nematicides, and soil amendments such as hardwood ashes and potash. The early work on sampling nematode communities provided a basis for the development of improved tactics and strategies essential for integrated nematode-pest management. In late nineteen century, it was offered to recommend for monitoring root-knot nematodes as well as for their management. A well-planned combination of practices will go much further for controlling nematodes than any of the recommended treatments alone ${ }^{[1]}$. It was further indicated that the presence of nematodes (root knot) in any soil can be determined by examining the roots of susceptible plants that have been growing for at least 3 weeks in warm, moist conditions. For attempted eradication of root-knot nematodes, it was suggested some innovative ideas like burning crop residues two or three times if possible, each preceded by a spading or plowing; dry fallowing, frequent ploughing, one or more well-irrigated trap crops completely destroyed 2 or 3 weeks after sprouting; moist fallow during warm weather, without weeds; resistant crops in rotation, kept free of weeds ${ }^{[2]}$.

It was also emphasized that root-knot nematodes enhanced the susceptibility of crops to such other diseases as cotton wilt, black shank of tobacco, and rhizoctonia disease of peanuts. These strategies/tactics were based on much earlier. Three key facets on which integrated pest management is based include: determining how the biology of a pest must be modified to reduce its density; combining current technology with biological knowledge to effect modifications, developing new or improved technologies for control that are compatible with economic circumstances and environmental requirements ${ }^{[3]}$.

Nematode management requires flexibility and must take into account species or races of nematodes, the availability of resistant or non-host plants, the cropping system and the cropping history, economics, and the climate. Although few nematode management practice are available, due to lack of hard data and variables such as nematicide dosage, costs of chemicals, efficacy of management tactics, and crop susceptibility, the outlook for integrated nematode management is positive ${ }^{[4]}$.

INM in chickpea crops against $M$. incognita

Many species of plant-parasitic nematodes have been reported in the roots and rhizosphere of chickpea in the major 
growing regions in the world. However, only certain nematode species are considered constraints to chickpea production, causing an estimated $14 \%$ in annual yield losses. The symptoms and signs of nematode parasitism on chickpea differ depending upon the nematode's feeding habit. Moreover, nematode attacks can make plants more sensitive to other biotic and abiotic stresses, and overall result in stunting and poor yield. Symptoms caused by nematode attack are nonspecific and nondescript, and they are largely a consequence of disruption of normal processes of plant growth, and absorption and translocation of water and nutrients. Consequently, damage by nematodes to chickpea often goes unnoticed and is attributed to other causes, such as lack of fertility or deficient soil moisture. For example, even $50 \%$ reductions in chickpea yield caused by the chickpea cyst nematode, Heterodera ciceri, cannot be predicted by inspection of the upper part of the plant. For these reasons, plant parasitic nematodes are often referred to as the "unseen enemies" of crops ${ }^{[4]}$. The most important nematode pathogens of chickpea include root-knot nematodes (Meloidogyne spp.), root-lesion nematodes (Pratylenchus spp.), cyst-forming nematodes (Heterodera spp.), and the reniform nematode (Rotylenchulus reniformis).

\section{Root-knot Nematodes in Chickpea}

Sedentary endoparasitic root-knot nematodes of the genus Meloidogyne are among nature's most successful plant parasites. Meloidogyne spp. infects thousands of different hosts, including herbaceous and woody monocotyledonous and dicotyledonous plants, and cause serious losses to numerous agricultural crops worldwide. The root-knot nematode species known to damage chickpea are $M$. arenaria, $M$. incognita, and $M$. javanica, a warm climate species that attack chickpea in the Indian subcontinent, and $M$. artiellia, a species well adapted to cool and wet conditions, which is widely distributed in the Mediterranean Basin. Root galling is the typical symptom of parasitism by Meloidogyne spp. in susceptible crops. However, compared with large galls induced by $M$. arenaria, $M$. incognita, and $M$. javanica on chickpea, M. artiellia produces small galls or no galls. The most evident sign in roots infected by this latter species are the egg masses produced by the nematode, which may contain 200 to 600 eggs. The limited hyperplasia in the vascular cylinder and the cortical cells that surround the feeding site of $M$. artiellia seems to determine the small gall size in this species ${ }^{[5]}$. Also, the frequently observed protrusion of bodies of adult $M$. artiellia females from infected roots, resembling the parasitic habit of adult cyst-nematode females, seems to be congruent with the lack of root galling Parasitism by root-knot nematodes in chickpea involves the establishment of permanent feeding sites called giant cells in the root cortex, endodermis, pericycle, and vascular parenchyma. Feeding sites are sinks for plant photosynthate. In addition, deformation and blockage of vascular tissues at feeding sites limit translocation of water and nutrients, and further suppress plant growth and reduce seed yield. In chickpea, the number of giant cells in the feeding site (averaging four to six) and the area of individual giant cells are not influenced by root-knot nematode species or isolates within species. However, the number of nuclei per giant cell is significantly lower for M. artiellia than for M. arenaria, M. incognita, or $M$. javanica. Similarly, maximum diameters of nuclei and nucleoli are significantly greater in giant cells induced by $M$. artiellia isolates compared with those induced by $M$. arenaria, M. incognita, or M. javanica ${ }^{[6]}$.

Uneven patches of chickpea plant growth are commonly associated with soils infested with root-knot nematodes. Heavily infected plants show stunted growth, less branching, and leaves with pale green to yellow color. The extent of yield loss caused by root-knot nematodes is determined by a number of factors, including the nematode species, the population density, pattern of nematode distribution in soil, the soil cropping history, chickpea cultivar, climate, and soil type. Although a variety of mathematical functions have been proposed to describe the relationships between the initial nematode population density in soil and crop damage, the most widely accepted one is the Seinhorst model $[y=m+$ $(1-\mathrm{m}) \mathrm{zP}-\mathrm{T}$ when $\mathrm{P} \geq \mathrm{T}$, and $\mathrm{y}=1$ when $\mathrm{P}<\mathrm{T}]$. In this model, $\mathrm{y}=$ relative value of the plant growth parameter being measured; $\mathrm{m}=$ the minimum value of $\mathrm{y}$ ( $\mathrm{y}$ at a very large initial nematode population density); $\mathrm{P}=$ the initial nematode population density; $\mathrm{T}=$ the tolerance limit (initial population at which plant growth is not impaired; and $\mathrm{z}=\mathrm{a}$ constant $<1$ reflecting nematode damage, with $\mathrm{z}-\mathrm{T}=1.05$. Threshold levels for $M$. incognita and $M$. javanica on chickpea grown under greenhouse conditions were established at 0.2 to 2.0 second stage juveniles $\left(\mathrm{J}_{2}\right)$ per gram of soil; however, tolerance to $M$. javanica was identified in some chickpea cultivars. Comparatively, the tolerance limits of chickpeas to infection by $M$. artiellia under field conditions in micro plot experiments were much lower, i.e., 0.14 and $<0.02$ eggs and $\mathrm{J}_{2}$ per $\mathrm{cm}^{3}$ of soil for winter- and spring-sown crops, respectively ${ }^{[7]}$. Chickpea yield losses of up to $60 \%$ were caused by severe $M$. incognita infections in India; whereas in southern Italy, initial M. artiellia populations of 2 eggs and $\mathrm{J}_{2}$ per $\mathrm{cm}_{3}$ of soil caused a yield reduction of $50 \%$ in winter sowings, and about $80 \%$ in spring sowings. Meloidogyne spp. attacking chickpea have a wide host range including many weeds, which constitute natural, alternative hosts for the nematodes and enable their survival and population increase. Moisture, texture, and temperature are major soil physical factors affecting distribution and reproduction of those nematodes. $M$. artiellia completes one generation per growing season, mostly because of a combination of low, insufficient rainfall and high temperature that prevail in spring in the Mediterranean Basin ${ }^{[8]}$.

\section{INM Packages}

A field trial was laid out in RBD with three replications comprising of 12 treatments including control using susceptible green gram CV. dhauli. A sub plot size of $4 \mathrm{~m} \mathrm{x}$ 
$3.1 \mathrm{~m}$ was maintained for each treatment. Observations were recorded on nematode population in soil and roots infested by root-knot nematode, Meloidogyne incognita. The initial nematode population in soil was 2.3 / g soil. The treatments were imposed 10 days after sowing (DAS) and observations on nematode population in the soil and roots of the infected plants were recorded at 45 DAS. Yield data were recorded at harvest. The results revealed that among the treatments, the combination of neem-cake + carbofuran + Pseudomonas fluorescens resulted maximum reduction of soil populations $(74.83 \%)$ and root population $(87.39 \%)$ over control followed by combination of neem cake + phorate + Pseudomonas fluorescens which recorded reduction in soil population $71.51 \%$ and root population $86.08 \%$ over control. Application of neem cake + phorate and combination of neem cake + carbofuran were significantly different from each other with respect to soil and root population. Application of carbofuran @ $2 \mathrm{~kg}$ a.ilha recorded 54.08\% reduction in nematode population in soil and $76.95 \%$ in roots followed by single application of phorate @ $2 \mathrm{~kg}$ a.i./ha. i.e. 48.92 and $70.43 \%$ in soil and root, neem cake @ $1.5 \mathrm{q} / \mathrm{ha}$ i.e. $47.84 \%$ and $67.39 \%$ in soil and root, Pseudomonas fluorescens@2.5 kg/ha i.e. $43.98 \%$ and $63.91 \%$ in soil and root and VAM@100 kg/ha i.e.39.03\% and 51.53\% in soil and root population, respectively over control.

The maximum yield was recorded by the combination of neem cake + carbofuran + pseudomonas fluorescens@ @2.5 $\mathrm{kg} / \mathrm{ha}$ and the percentage increase was $81.82 \%$ over control . The combination of neem cake + phorate, neem cake + carbofuran and neem cake + pseudomonas fluorescens were significantly different from each other. The present results suggested that combined application of neem cake + carbofuran + Pseudomonas fluorescens was most effective in reducing nematode population and subsequent increase in yield than individual applications. This might be due to the nematicidal and nutritional components of neem cake released during decomposition and growth promoting activity and carbohydrate-lectin metabolism of Pseudomonas fluorescens ${ }^{[9,24]}$. The plant growth promoting rhizobacteria produce iron-chelating siderphos antibiotics or hydrogen cyanide and these compounds have been implicated in reduction of pathogenic rhizospheric micro-organisms creating an environment favourable for root growth. These rhizobacteria reduce the hatching and invasion due to the production of toxic metabolites inside the plant. The effectiveness of neem cake in the control of Meloidogyne incognita and Rotylenchulus reniformis was reported by many workers ${ }^{[10]}$.

\section{New Technologies for Pulses Nematode Management}

As sustainable nematode management becomes increasingly based on soil biology and soil health, new complementary technologies are developing. These new tools undoubtedly will improve the accuracy of nematode diagnoses and assessments of potential problems, and will result in more effective management, reduced pesticides, pesticide usage, and less contamination of groundwater with agricultural chemicals such as nematicides, nitrogen, and fertilizers ${ }^{[11]}$.

\section{Precision Agriculture}

Modern computerized harvest-management and data systems offer new opportunities for more precise management of nematodes and general crop production. This technology has the potential to improve water use and limit fertilizer and pesticide application on a spatial and temporal basis as dictated by soil fertility and, more important, differential spatial crop yields. Based on early results, this management tool should allow specially prescribed nematode control in high-intensive crop production such as Radopholus similis on banana (DH Marin-Vargas, personal communication) and root-knot nematodes on potato in the northwestern United States. Approaches that focus on a harvest index to locate environmental stress should be able to relate nematode kinds and numbers to poor yield and other stress factors. This approach is now being used in some banana operations in which fruit is harvested in small subunits and yield data are recorded and analyzed by computer (DH Marin-Vargas, personal communication). Poor-yielding sections can be examined for nematode densities and other potential problems ${ }^{[12]}$.

\section{Nematode Identifications and Population Assessments}

The tools of rDNA technology, especially when allied with traditional taxonomic characters and host differentials, have greatly facilitated identification of nematode species and often host race. Isolated specimens of a range of nematode species have been identified by differential isozyme pattern and/or specific DNA probes, and there has been some progress in identifying and quantifying nematodes from processed soil samples. Continuing restrictions in the size of samples and numbers of nematodes that can be examined make it very difficult to fully diagnose the nematode species present in large fields. However, this new technology should facilitate a more complete characterization of the diverse nematode trophic groups and species that are affected by disturbance and management practices in various ecosystems ${ }^{[13]}$. The availability of mobile soil-samplers, especially when used in precision production systems, could facilitate more directed, selective sampling for general nematode assays and identifications. Geostatistical analyses could be interfaced with these improved sampling apparatus for more precise measurement of data on nematode population. Image analysis has been adapted to count specific nematodes, but differentiating species with computers currently available would be too 
time-consuming ${ }^{[14]}$.

Genetically engineered and traditional host resistance

The increasing complexity and costs of genetic engineering of plants for pest resistance or altering biocontrol agents make it unlikely that significant economic repercussions of molecular biology will be felt on agricultural production in the near future. There has been considerable progress made in engineering host resistance to nematodes, genetic mapping, and diagnostics. However, genetically engineered resistance to nematodes is still at the developmental stage in contrast to the recently deployed herbicide- and insect-resistant cultivars of cotton, soybean, and other crops ${ }^{[15]}$. One strategy involves transformation of plants with a transgene(s) encoding a product detrimental to the target nematode or that suppresses the expression of key plant genes involved in the nematode-host interaction. Candidate genes for this strategy include collagenase, genes expressed in the development of specialized feeding cells induced by species of Globodera or Heterodera (syncytia) and Meloidogyne (giant cells). Constructs of the root-specific TobRB7 gene in tobacco have been used to develop promising root-knot nematode-resistant genotype. Linking this gene with a BARNASE gene resulted in root knot-resistant plants, but difficulties were encountered in recovering resistant lines from progeny of the transformants. Transformed plants with an antisense TobRB7 construct also exhibited root-knot resistance; root-gall development was about $70 \%$ less in than susceptible plants ${ }^{[16,23]}$.

\section{Advisory Programs}

Despite the development of nematode advisory programs in some states in the United States in the 1960s and earlier elsewhere, low-cost, highly effective nematicides remained in use as a form of insurance until recently ${ }^{[17]}$. The unreliability of nematode assays, due to difficulties in sampling the contagious infestations, identification of related species, and lack of information on economic thresholds helped to prolong nematicides use ${ }^{[18]}$. Nevertheless, advisory programs have successfully contributed to lower pesticide usage and greater farm profits. Management of nematodes, including advisory programs, poses greater challenges for perennial crops than for annual crops. Control options are limited, and very low population densities often build up to cause severe damage over time. Integrated management, including assays to determine numbers and kinds of nematodes present, and appropriate control tactics such as preplant fumigation where necessary, use of nematode-free stock, tolerant cultivars where available, and organic mulches are useful for woody ornamentals ${ }^{[19,20,21,22]}$.

\section{Conclusions}

New approaches to nematode control hold great promise for sustainable, integrated crop-pest-management systems.
Rapidly evolving knowledge and understanding of soil biology and crop molecular biology can be exploited in highly productive, intensive cropping systems. The challenge is to develop primary cover-crop, animal-waste, tillage systems that result in the build-up of favorable rhizobacteria, fungi, nematodes, protozoa, earthworms, and other fauna while also suppressing plant-parasitic nematodes and other crop pathogens. Combining this new, integrated soil biology-based nematode-pest-crop management with traditional and/or genetically engineered host resistance and cultural practices such as rotation should reduce the need for pesticides. However, worldwide the area dedicated to crop production is unlikely to expand during the next two decades; on the contrary, there is a continuous and substantial decline in grain-producing area per person. Thus, food production per hectare must be increased. In conclusion, the development of sustainable nematode-management systems is not an option. It is imperative that scientists devise the requisite sustainable tactics as one component of the world's complex food-fiber production system to meet the pressure of the rapid population increase. Management of plant-parasitic nematodes is essential to sustainability, since impaired efficiency of plants' water and nutrient utilization caused by these pathogens limits production and degrades the environment. The proposed strategy of increased use of pesticides and plastics to meet this challenge would likely provide only short-term benefits. For example, the repeated heavy use of chemicals such as methyl bromide essentially sterilizes the soil and eliminates beneficial soil micro-flora and fauna as well. Many other current crop- and pest-management practices also contribute to the instability of our food production. Fortunately, the new technologies forthcoming from molecular and soil biology and truly integrated cropping-nematode-pest management systems are providing new strategies and tactics that can be linked to traditional nematode management for more general integrated and sustainable food and fiber production. In fact, the wide gaps between and within developing and developed countries indicate that global food production still can be increased.

\section{REFERENCES}

[1] Abawi G.S. and J. Chen. 1998. Concomitant pathogen and pest interactions. Crop Science, Society of America. 34:135158.

[2] Alphei J., M. Bonkowski, and S. Scheu. 1996. Protozoa, nematoda and lumbric'idea in the rhizosphere of Hordelymus europaeus (Poaceae): faunal interactions, response of microorganisms and effects on plant growth. Oecologia.106:111-126.

[3] Alston D.G., J.R. Bradley, D.P. Schmitt, and H.D. Coble. 1991. Response of Helicoverpa zea(Lepidotera Noctuidae) populations to canopy development in soybean as influenced by Heterodera glycines(Nematoda: Heteroderidae) and 
annual weed population densities. Journal of Economic Entomology.84:267-276.

[4] Anand, S.C., S.R. Koenning, and S.B. Sharma. 1995. Effect of temporal deployment of different sources of resistance to soybean cyst nematode. Journal of Productive Agriculture. $8: 33-34$.

[5] Anand, S.C., S.R. Koenning, and S.B. Sharma. 1995. Performance of blends of soybean cyst nematode resistant and susceptible soybean cultivars. Crop Science.35:524-528.

[6] Atkinson, G.F. 1889. A preliminary report upon the life-history and metamorphorses of a root-gall nematode, Heterodera radicicola (Greef) M"uller, and the injuries caused by it upon the roots of various plants. Bullal Alanol Polytech Institute., N. S. No. 9.

[7] Avery, D.T. 1995. Saving the Planet with Pesticides and Plastic. Indianapolis: Hudson Institute. pp. 432.

[8] Baird, S.M. and E.C. Bernard. 1984. Nematode population and community dynamics in soybean-wheat cropping and tillage regimes. Journal of Nematology. 16:379-386.

[9] Bakker, J., F.J. Gommers, L. Smits, A. Fuchs, and F.W. DeVries. 1983. Photoactivation of isoflavonoid phytoalexins: involvement of free radicals. Phytochemical Phytobiology. $38: 323-329$.

[10] Barker, K.R. 1985. Sampling nematode communities. In An Advanced Treatise on Meloidogyne, Coop. Publ. Dep. Plant Pathology, NC State Univ./US AID, Raleigh, NC. Vol. II. pp. 3-17.

[11] Barker, K.R. 1989. Yield relationship and population dynamics of Meloidogyne spp. on flue-cured tobacco. Journal of Nematology. 21:597-608.

[12] Barker, K.R. and E.L. Davis. 1996. Assessing plant nematode infestations and infections. In Advances in Botanical Research (incorporating Advances in Plant Pathology). 23:103-36.

[13] Barker, K.R. and J.L. Imbriani. 1984. Nematode advisory programs- status and prospects. Plant Disease. 68:735-741.
[14] Barker, K.R., G.A. Pederson, and G.L. Windham. 1998. Plant and Nematode Interactions. American Society of Agronomy. 64:142-149.

[15] Been, T.H., M.J. Meijer, A.E. Beniers, and J.W. Knol. 1996. Using image analysis for counting larvae of potato cyst nematodes (Globodera spp.). Fundamental Applied Nematology. 19:297-304.

[16] Belair, G. and D.L. Benoit. 1996. Host suitability of 32 common weeds to Meloidogyne hapla in organic soils of southwestern Quebec. Journal of Nematology. 28:643-647.

[17] Benson, D.M., and K.R. Barker. 1985. Nematodes- a threat to ornamental plants in the nursery and landscape. Plant and Disease. 69:97-100.

[18] Bessey, E.A. 1911. Root-knot and its control. US Department of Agricultural Bureau. Plant and Bulletin. 217:89.

[19] Bird, G.W. 1987. Role of nematology in integrated pest management programs. Journal of Nematology. 164:114-121.

[20] Chitwood, D.J. (2002). Phytochemical based strategies for nematode control. Ann. Rev. Phytopathol. 40: 221-249

[21] khtar, M. (2000). Nematicidal potential of the neem tree Azadirachta indica (A.Juss). Intrgd. Pest Management Rev. 5: 57-66.

[22] Osei, K., Moss, R., Nafeo, A., Addico, R., Agyemang, A., Danso, Y. and Asante J.S. (2011). Management of plant parasitic nematodes with antagonistic plants in the forest-savanna transitional zone of Ghana. J. Appl. Biosci. 37: $2491-2495$

[23] Tariq, I. and Siddiqui, M.A. (2005). Evaluation of nematicidal properties of neem for the management of Meloidogyne incognita on tomato .Indian J. Nematol. 35:56-58.

[24] Yadav,Y.S.,Siddqui,A.U.\&Parihar, A.(2006).Efficacy of Oil Cakes as Seed Dressing Treatment For the Management of Root -Knot Nematode M . incognita affecting Chickpea. Indian J. Nematol. 36:151 -152. 